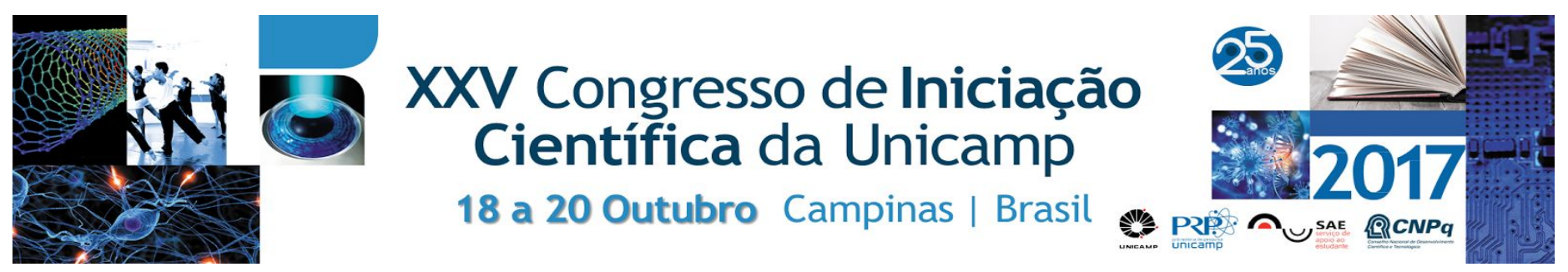

\title{
Produção mais Limpa em Habitação de Interesse Social
}

\section{Eloisa Dezen Kempter*, Rafaela Luiza Pereira, Rayan Nascimento Teixeira, Vinícius Motta Martins.}

\section{Resumo}

Este projeto teve o objetivo de realizar uma pesquisa com foco em produção mais limpa $(P+L)$ em Habitação de Interesse Social, em um projeto do Programa Minha Casa Minha Vida (PMCMV), no bairro Geada em Limeira/SP. A pesquisa visou obter informações sobre os conceitos de valor e alterações realizadas no ambiente habitacional, de forma a avaliar as possibilidades de melhoria das condições da unidade habitacional entregue e direitos dos cidadãos.

Palavras-chave: Conceitos de Valor, Ambiente Habitacional, Produção mais Limpa.

\section{Introdução}

Este projeto pretende aliar dois temas de relevância: habitação de interesse social e sustentabilidade na construção civil. Portanto tem como alvo principal prestar suporte técnico, aos proprietários dos lotes urbanizados e das casas do programa Minha Casa Minha Vida, empregando práticas de produção mais limpa $(\mathrm{P}+\mathrm{L})$, reduzindo impactos ambientais e o custo da obra.

Para a coleta de dados sobre o local e seus habitantes foi empregada uma técnica de pesquisa com entrevistas semiestruturadas auxiliadas por cartões ilustrados. Deste modo o respondente tem a condição de hierarquizar as alternativas à sua disposição, favorecendo as pesquisas. Com isso foram obtidos resultados sobre as satisfações dos indivíduos e características das moradias.

\section{Resultados e Discussão}

Os resultados da pesquisa realizada no bairro revelou a diversidade de grupos familiares, apresentando de 1 a 8 membros, com destaque para a combinação de 4 e 5 pessoas. A figura 1 apresenta a distribuição da composição familiar da amostra, com a distribuição percentual de famílias para cada um dos grupos

Figura 1. Grupos Familiares.

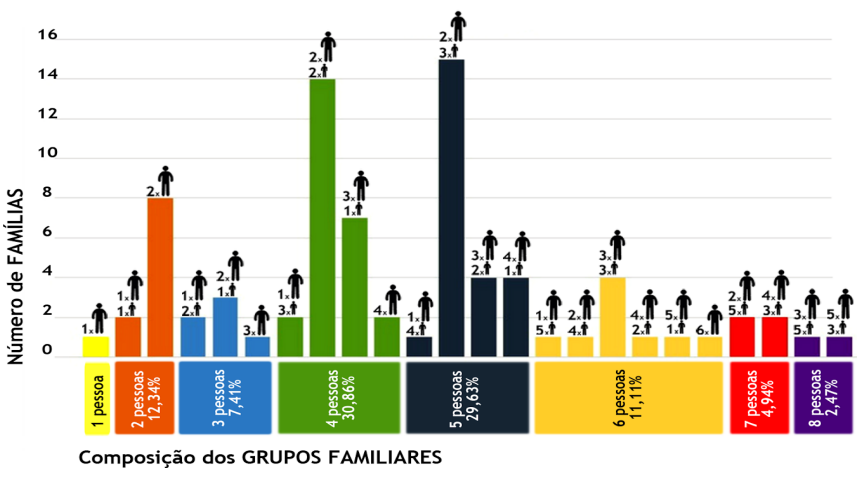

Mesmo com a satisfação declarada da população com a casa entregue, devido à variação dos grupos familiares, o tamanho e distribuição dos ambientes foram alvos de ajustes para atender às necessidades de cada família, conforme podemos constatar nas ampliações realizadas (Fig. 2)

Figura 2. Ampliações Realizadas.

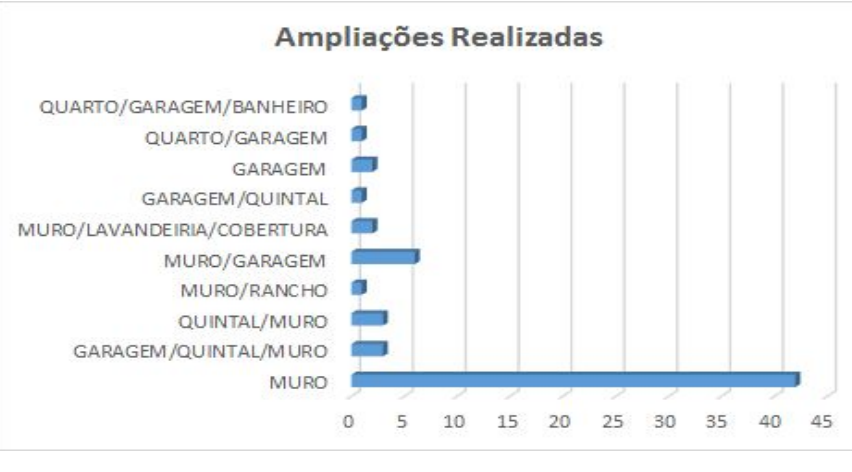

\section{Conclusões}

A partir das aferições estatísticas, pode-se avaliar o que os moradores consideram prioridade e suas necessidades espaciais. Com base nos resultados obtidos, concluímos que a questão da habitação de interesse social precisa ser tratada de forma diferente.

Foi proposto um projeto de unidade habitacional que busca a melhoria da qualidade do ambiente, oferecendo soluções para a população atendida, possibilitando a flexibilidade espacial e atendendo necessidades dos grupos familiares específicos.

Portanto chegamos a uma compreensão entre a dualidade das necessidades dos indivíduos em questão e questões de ordem socioeconômica e custeio-meta estabelecidas pela prefeitura de Limeira e órgãos de fomento habitacional.

\section{Agradecimentos}

Agradecemos aos bolsistas SAE que nos auxiliaram no desenvolvimento desta pesquisa, Tamires Almeida, Rodrigo Nascimento, Matheus Santos, Davi da Silva, Robson Pereira. Assim como, à graduanda Erica de Matos, cuja pesquisa está integrada a nossa.

Agradecemos à Unicamp e à Faculdade de Tecnologia por propiciar esta experiência acadêmica de pesquisa e oferecer um ambiente criativo e amigável. 